\title{
Subionospheric early VLF perturbations observed at Suva: VLF detection of red sprites in the day?
}

\author{
Sushil Kumar, ${ }^{1}$ Abhikesh Kumar, ${ }^{1}$ and Craig J. Rodger ${ }^{2}$ \\ Received 16 August 2007; revised 21 November 2007; accepted 13 December 2007; published 26 March 2008.
}

[1] First observations of early Very Low Frequency (VLF) perturbations on signals from NWC $(19.8 \mathrm{kHz})$ and NPM $(21.4 \mathrm{kHz})$ monitored at Suva, in the month of November 2006, are presented. The early/fast, early/slow, early/short (RORD), and step-like early VLF perturbations are observed on signals from both the transmitters. The early/fast VLF events are found to occur more often in the nighttime than in the daytime whereas step-like early events predominantly occur in the daytime. Most of the early VLF events are associated with amplitude changes between $0.2-0.8 \mathrm{~dB}$ with only a few cases $>0.8 \mathrm{~dB}$. In general, the recovery time of daytime early/fast VLF events is less when compared to the nighttime early/fast VLF events. The lightning location data provided by the World-Wide Lightning Location Network and broadband VLF data recorded at Suva have been analyzed to identify the location of causative lighting discharges along the great circle paths between transmitter and receiver, and the sferics associated with causative lightning of early VLF events. This research is the first to report both daytime early/fast VLF perturbations with faster recovery and also step-like early VLF perturbations initiated and ended by the lightnings which are most likely associated with red sprites and/or elves occurring in the daytime.

Citation: Kumar, S., A. Kumar, and C. J. Rodger (2008), Subionospheric early VLF perturbations observed at Suva: VLF detection of red sprites in the day?, J. Geophys. Res., 113, A03311, doi:10.1029/2007JA012734.

\section{Introduction}

[2] The Very Low Frequency (VLF) radio signals generated by navigational transmitters and lightning discharges propagate by multiple reflections in the waveguide bounded by the Earth's surface and the lower region of the ionosphere. The measurements of amplitude and phase of the VLF transmission provide information on the long and short timescale variations of VLF signal strength and hence on the D-region of the ionosphere. The short time-scale ( 100 s) VLF amplitude and/or phase perturbations, so-called Trimpi, were first recognized by M. L. Trimpi in the VLF data recorded in Antarctica and have been discussed by Helliwell et al. [1973]. Helliwell et al. [1973] related such Trimpis (now termed "classic or WEP Trimpi") to the precipitation of energetic electrons into the lower ionosphere near the nighttime VLF reflection heights $(\sim 80-90 \mathrm{~km})$ from radiation belts due to whistler-electron interactions. The onset time delay of classic Trimpi $(\sim 1 \mathrm{~s})$ was related to the time of whistler sferic propagation, interaction with electrons in the radiation belt, and electron precipitation, while their slow decay $(\sim 100 \mathrm{~s})$ was related to the slower charge density relaxation in the ionosphere. Armstrong [1983] discovered a new type of VLF perturbation whose onset was too soon

\footnotetext{
${ }^{1}$ School of Engineering and Physics, The University of the South Pacific, Suva, Fiji.

${ }^{2}$ Department of Physics, University of Otago, Dunedin, New Zealand.

Copyright 2008 by the American Geophysical Union. 0148-0227/08/2007JA012734\$09.00
}

(early) after the causative lightning in comparison to classic Trimpi and had comparatively faster decay time. This class of Trimpi is now referred as "early" Trimpi [Inan et al., 1988] or early VLF perturbation. The early VLF perturbations caused by direct lightning effects on the ionosphere are very common perturbations in active thunderstorm regions, and are caused by scattering from localized regions of the ionization enhancements in the lower region of the ionosphere due to the strong lightnings producing transient luminous events (TLEs) particularly associated with sprites and elves. The scattering in some cases shows a narrowangle due to ionization enhancements by lightning discharges occurring at distances of about $\pm 50 \mathrm{~km}$ off the transmitter receiver great circle path (TRGCP) [Inan et al., 1993, 1995, 1996a, 1996b], or in other cases show wideangle including backscatter due to ionization enhancements by lightning discharges occurring at distances of less than $500 \mathrm{~km}$ off the TRCGP and around the receiver [Dowden et al., 1996; Hardman et al., 1998; Rodger, 2003]. The discovery of transient luminous events (TLEs) including optical emissions of red sprites established the mechanisms of direct lighting ionization enhancements in the lower ionosphere [Sentman et al., 1995; Wescott et al., 1995]. The early VLF perturbations associated with sprites were first reported by Inan et al. [1988] from the Trimpi measurements made over United States. It is now believed that sprites in the lower ionosphere have nearly one-to-one correlation with early/fast VLF perturbations [Dowden et al., 1996; Inan et al., 1996a, 1996b; Mika et al., 2005]. Rodger [2003] presented a detailed review on the VLF 


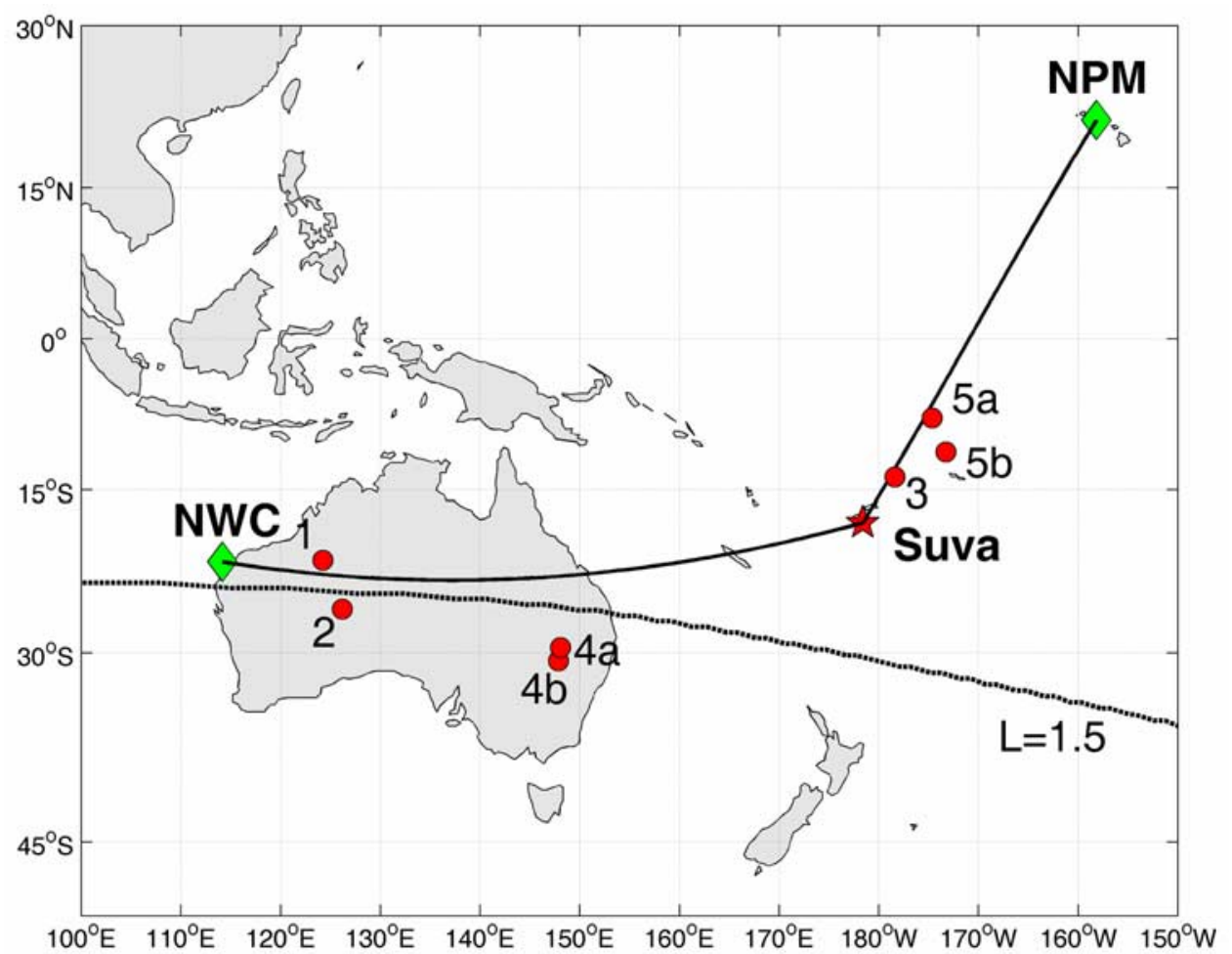

Figure 1. The locations of NWC and NPM transmitters, receiver, and great circle paths to Suva. A contour for $\mathrm{L}=1.5$ is also plotted. The numbers mark the WWLLN-determined locations of the lightnings associated with early VLF perturbations.

perturbations associated with lightning discharges. Recently, Mika et al. [2006] from the observations taken during EuroSprite2003 have reported the early VLF perturbations associated with elves.

[3] In this paper, we present initial observations of early VLF perturbations on the $19.8 \mathrm{kHz}$ signal from NWC $\left(21.8^{\circ} \mathrm{S}, 114.1^{\circ} \mathrm{E}, 1 \mathrm{MW}, L=1.44\right)$ and the $21.4 \mathrm{kHz}$ signal from NPM $\left(21.5^{\circ} \mathrm{N}, 158.1^{\circ} \mathrm{W}, 0.5 \mathrm{MW}, L=1.17\right)$ communication transmitters observed in Suva $\left(18.1^{\circ} \mathrm{S}\right.$, $\left.178.5^{\circ} \mathrm{E}, L=1.16\right)$, Fiji, in the month of November 2006. We have used $0.1 \mathrm{~s}$ resolution data of amplitude and phase throughout 1-30 November 2006 to study different types of early VLF perturbations both during night and day.

\section{Experimental Set-Up and Data}

[4] We use World-Wide Lightning Location Network (WWLLN) VLF system originally set-up for global lightning detection at The University of the South Pacific, Suva, Fiji, to receive radio signals from VLF transmitters. The WWLLN system consists of a short $(1.5 \mathrm{~m})$ whip antenna, pre-amplifier fixed at the bottom of the whip antenna, and VLF service unit (SU) coupled with pre-amplifier. Dowden et al. [2002] have described the details of WWLLN instrumentation and measurement technique of Time of Group Arrival (TOGA) of sferics at multiple sites. SU unit has two parallel outputs and one of the SU outputs is used to record the amplitude and the phase of the VLF signals using Software based Phase and Amplitude Logger (termed a "SoftPAL"). SoftPAL can log phase and amplitude of seven MSK transmitters continuously with time resolutions rang- ing from $10 \mathrm{~ms}$ to $10 \mathrm{~s}$ using GPS based timing. The continuous recording of phase and amplitude variations provides the diurnal and short time-scale changes of ionization properties in the lower ionosphere along the signal paths. The NWC and NPM signals are recorded at $0.1 \mathrm{~s}$ and are run continuously using Chart for Windows software. The continuous operation is chosen to monitor the diurnal variation in the signal strength and to study night and daytime VLF perturbations. The locations of the transmitters, receiver, and TRGCPs to Fiji are shown in Figure 1. The TRGCP propagation distance is $7.4 \mathrm{Mm}$ for NWC and $5.4 \mathrm{Mm}$ for NPM. A typical example of the diurnal variation of the 1 minute averaged amplitude and phase values for the NWC and NPM signals in decibels and degrees respectively is shown in Figures $2 \mathrm{a}$ and $2 \mathrm{~b}$ on 21 November 2006. It was geomagnetically a quiet day with maximum three hourly $K_{p}$ value of $1 \ldots$. It can be seen from Figure 2 that the rapid changes in phase took place at the time of the amplitude minima and change in phase was in the direction of decreasing phase delay during sunrise and increasing phase delay during sunset. During the time of sunrise and sunset transitions along the transmission path three amplitude minima during sunrise and sunset labeled as $\mathrm{SR}_{1}, \mathrm{SR}_{2}, \mathrm{SR}_{3}$ and $\mathrm{SS}_{1}, \mathrm{SS}_{2}, \mathrm{SS}_{3}$ respectively on NWC signal and one minima each during sunrise and sunset on NPM signal, are observed. The NWC signal strength is larger in the nighttime as compared to the daytime whereas NPM signal strength is larger in the daytime. There was power dropout for NPM transmitter around 8 and $11 \mathrm{~h} \mathrm{UT}$ which is not a regular occurrence. The local time of Fiji is $\mathrm{LT}=\mathrm{UT}+12 \mathrm{~h}$. Signal minima during the sunrise and 

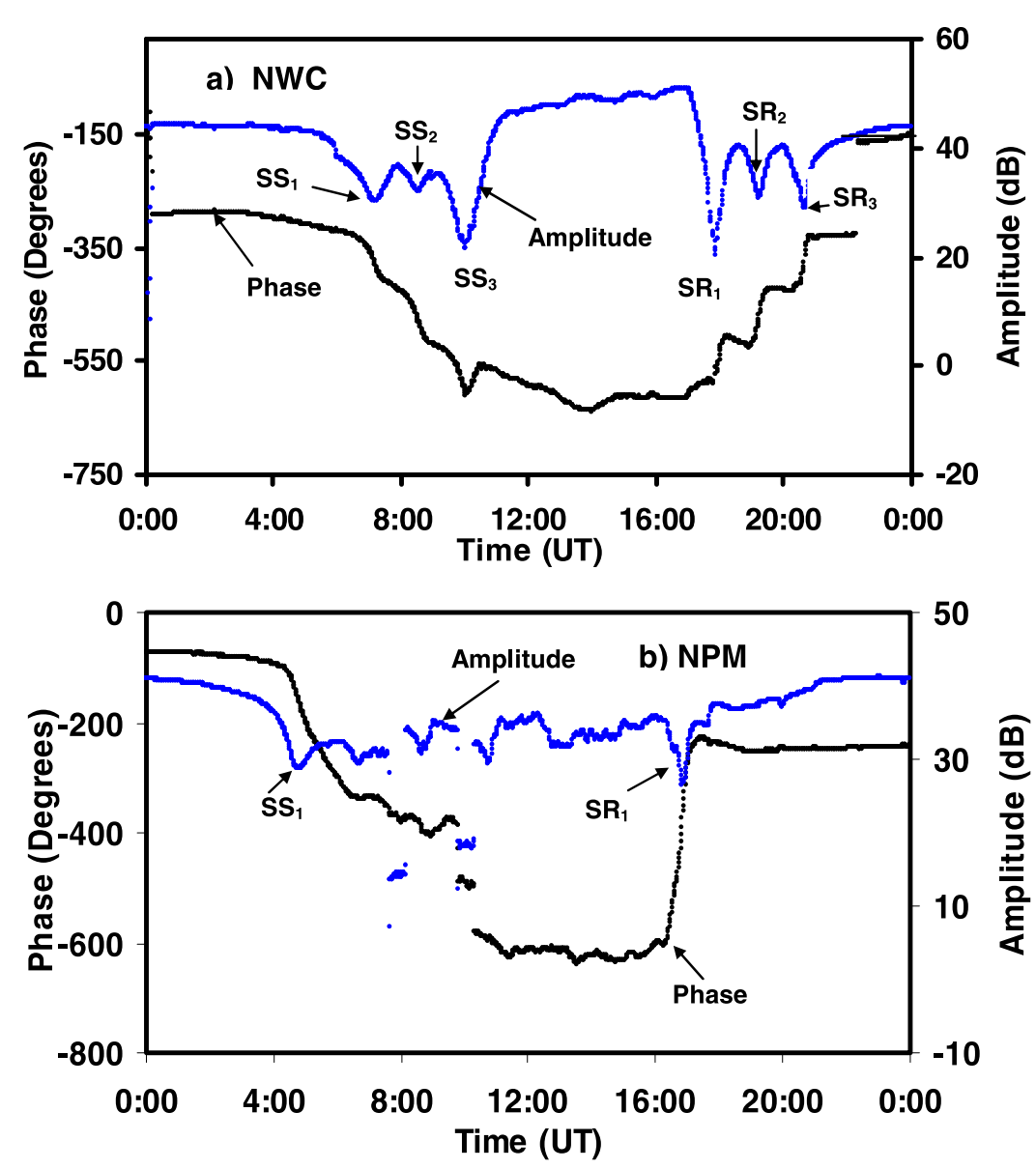

Figure 2. Typical variation of amplitude and phase of NWC and NPM signals on 21 November 2006.

sunset transitions observed on long propagation paths are due to the destructive interference of daytime and nighttime modes at the terminator [Crombie, 1964; Clilverd et al., 1999]. The number of sunset and sunrise minima depends on the distance propagated by signals along the east-west direction or vice versa.

\section{Observational Results}

\subsection{Overview of Early VLF Perturbations}

[5] The TRGCPs of NWC and NPM are in the region of $L<1.5$ where the electron precipitation causing LEPproduced VLF perturbations (classic Trimpi) is very unlikely. This is supported by the observations of several hundred LEP bursts by the low-altitude S81-1 satellite, with no events occurring below $L \sim 1.8$ [Voss et al., 1998]. Therefore, we consider that all the VLF perturbation events presented here are early VLF perturbation events. The short time-scale perturbations in the amplitude and/or phase of the NWC and NPM signals received at Suva clearly reveal the characteristics of early VLF perturbations that include early/ fast, early/slow, early/short (RORD) as well as step-like early VLF perturbations, which are reported here for the first time. In the current study we have excluded further consideration of so-called early/short Trimpis or RORDs perturbations, and focus on VLF perturbations with longer time signatures, which are more clearly defined in observations. It is found that early/fast VLF events occur most often in our observa- tions from Suva, early/slow events are very rare, and steplike early events mainly occur in the daytime. Shown in Figures $3 \mathrm{a}$ and $3 \mathrm{~b}$ are absolute amplitude changes associated with early VLF events on NWC and NPM signals obtained from the analysis of data in the period of 1-15 November 2006. Most of the early VLF events are associated with absolute amplitude change between 0.2 and $0.8 \mathrm{~dB}$, with a few cases of $\geq 1.0 \mathrm{~dB}$, which is in line with occurrence statistics for early/ fast events [e.g., Moore et al., 2003; Mika et al., 2005].

\subsection{Nighttime Early VLF Perturbations}

[6] As has been reported previously, early VLF perturbation events occur more frequently at times when entire TRGCP or a part of it is in dark. Indeed, up to now very few VLF perturbations have ever been reported during day time propagation conditions due to the dominance of the Sun as an ionization source. We present here the typical early VLF events observed when significant portion of TRGCP was in dark up to the location of lightnings associated with early VLF events. Figure 4 presents typical early VLF events associated with amplitude increase or decrease and phase advance or retard, observed on the NWC and NPM signals in the nighttime: (a) on 22 November 2006 at 12:38:33.2 h UT on NWC, (b) on 29 November 2006 at 18:04:10.9 h UT on NWC, (c) on 23 November at 13:02:32.6 h UT on NWC, (d) on 10 November 2006 at 10:48:01.2 h UT on NPM, (e) on 9 November 2006 at 16:06:56.1 h UT on NPM, (f) on 23 November 2006 at 14:02:07.7 h UT on NPM. The solid 

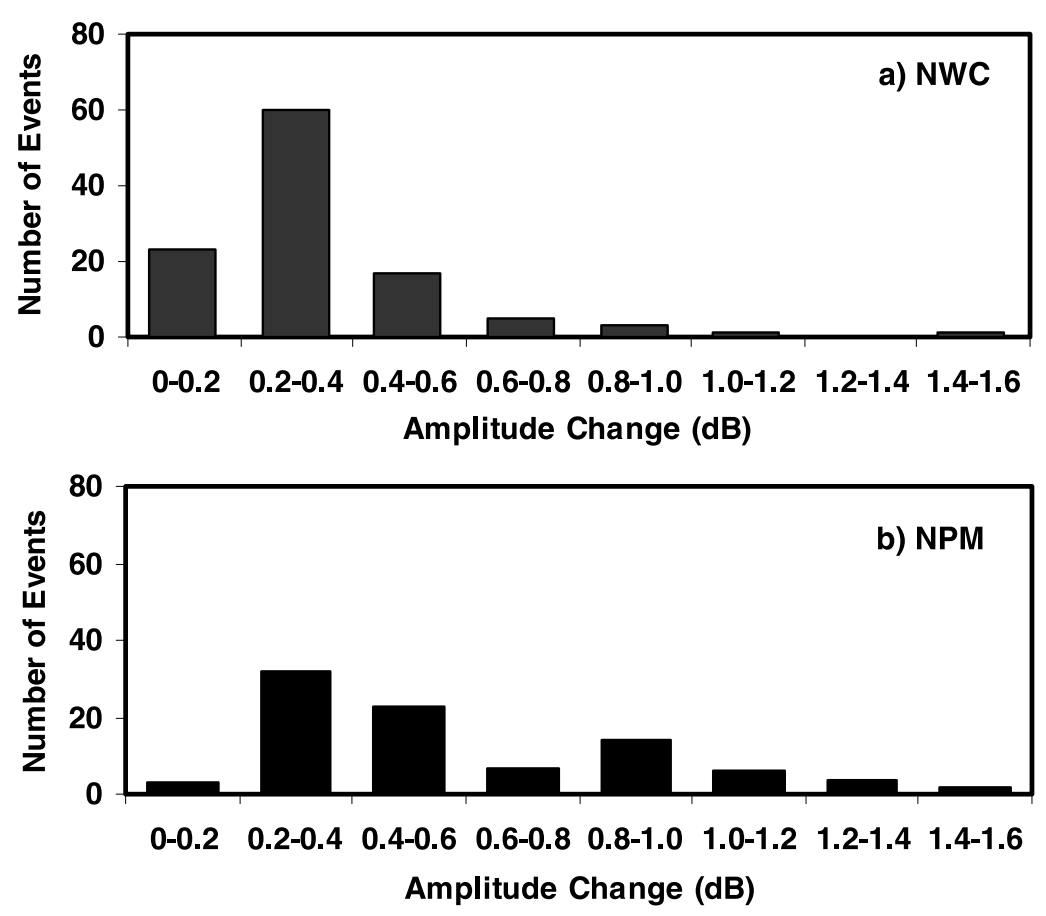

Figure 3. Change in absolute amplitude of VLF events observed during 1-15 November 2006, (a) on NWC signal, (b) on NPM signal.

traces (blue) and dotted traces (red) represent the amplitude and phase plots respectively. The vertical dashed lines with arrows in panels $(a, b, d)$ indicate the time of WWLLN-detected lightnings associated with these perturbations. The vertical solid lines with arrows in panels (c, f) indicate the time of radio sferics observed at Suva. In general, the decay rate of early/fast events on NWC signal is faster than the decay rate of such events on NPM signal as can also be seen from this figure. The VLF event presented in panel $\mathrm{c}$ is an early/slow event and others are early/fast events. The early/fast events display an instant (fast) onset of about $100 \mathrm{~ms}$ followed by the usual recovery of several tens of seconds whereas the early/slow event in panel c shows gradual onset of about $0.5 \mathrm{~s}$ on amplitude and about $1.1 \mathrm{~s}$ on phase. The early/fast and early/slow events are characterized by short $(100 \mathrm{~ms})$ and long $(0.5-2.5 \mathrm{~s})$ onsets respectively [Haldoupis et al., 2004, 2006]. To identify the causative lightning for these early VLF events, we analyzed WWLLN data along the TRGCPs near the time of occurrence of perturbations. WWLLN detects the global lightnings with return stroke currents of more than $\sim 50 \mathrm{kA}$ with spatial and temporal accuracy of roughly $10-20 \mathrm{~km}$ and $10 \mu$ s respectively and has detection efficiency less than $4 \%$, although a much higher detection efficiency for high peak current lightning [Rodger et al., 2006]. The processing center of WWLLN provides the participating Institutions with monthly data of lightning locations and the stroke times (accurate to $\mu \mathrm{s}$ ), on a CD. WWLLN confirms a lightning strike only when 4 or more stations record the same lightning, and at present 28 universities/institutions all over the world are participating in WWLLN. WWLLN detected a lightning event on 22 November 2006 at 12:38:33.135945 h UT, geog. lat. -21.6418 , geog. long. 124.2523 that produced the early/ fast VLF event on NWC signal shown in panel a of Figure 4. The location of this lightning has been marked by " 1 " in
Figure 1 which is near the NWC transmitter and within a distance of 50-100 km perpendicular to TRGCP (NWCSuva). WWLLN detected a lightning event on 29 November 2006 at 18:04:10.867713 h UT, geog. lat. -26.1643, geog. long. 126.1985 which was coincident with the early/fast event on NWC signal shown in panel $b$ of Figure 4 . The location of this lightning has been marked by " 2 " in Figure 1 which is near to the NWC transmitter and within a distance of 300-350 km perpendicular to TRGCP (NWC-Suva). A lightning was detected by WWLLN on 10 November 2006 at 10:48:01.194528 h UT, geog. lat. -13.7828 , geog. long. -178.373 coinciding with the early/fast event on NPM signal shown in panel d of Figure 4. The location of this lightning has been marked by " 3 " in Figure 1 which is near to the receiver and at a perpendicular distance of about $50-100 \mathrm{~km}$ from TRGCP (NPM-Suva). WWLLN did not detect the lightning locations associated with remaining early VLF events shown in Figures 4c, 4e and 4f, however, radio sferics were observed for VLF events in panels $\mathrm{c}$ and $\mathrm{f}$. In general, for about $5 \%$ of the total early VLF perturbation events observed at our station, WWLLN detects the associated lightning with locations along the TRGCP and around the receiver. This could be due to the low detection efficiency of WWLLN. Using the WWLLN program installed in WWLLN PC at our station we can also record the wideband VLF data that can be analyzed using MATLAB code which gives one spectrogram every second. The wideband VLF data were recorded at our Suva station for $5 \mathrm{~min}$ at every hour in the nighttime (18-06 h LT) during the month of November 2006. The early/slow event on NWC signal shown in panel c occurred during the time of wideband data recording. The analysis of VLF data revealed the sferics on 23 November at 13:02:32.54 h UT coincident with the time of occurrence of this early/slow event. Figure 5a shows the spectrogram having the sferics (small cluster), coincident with the early/ 

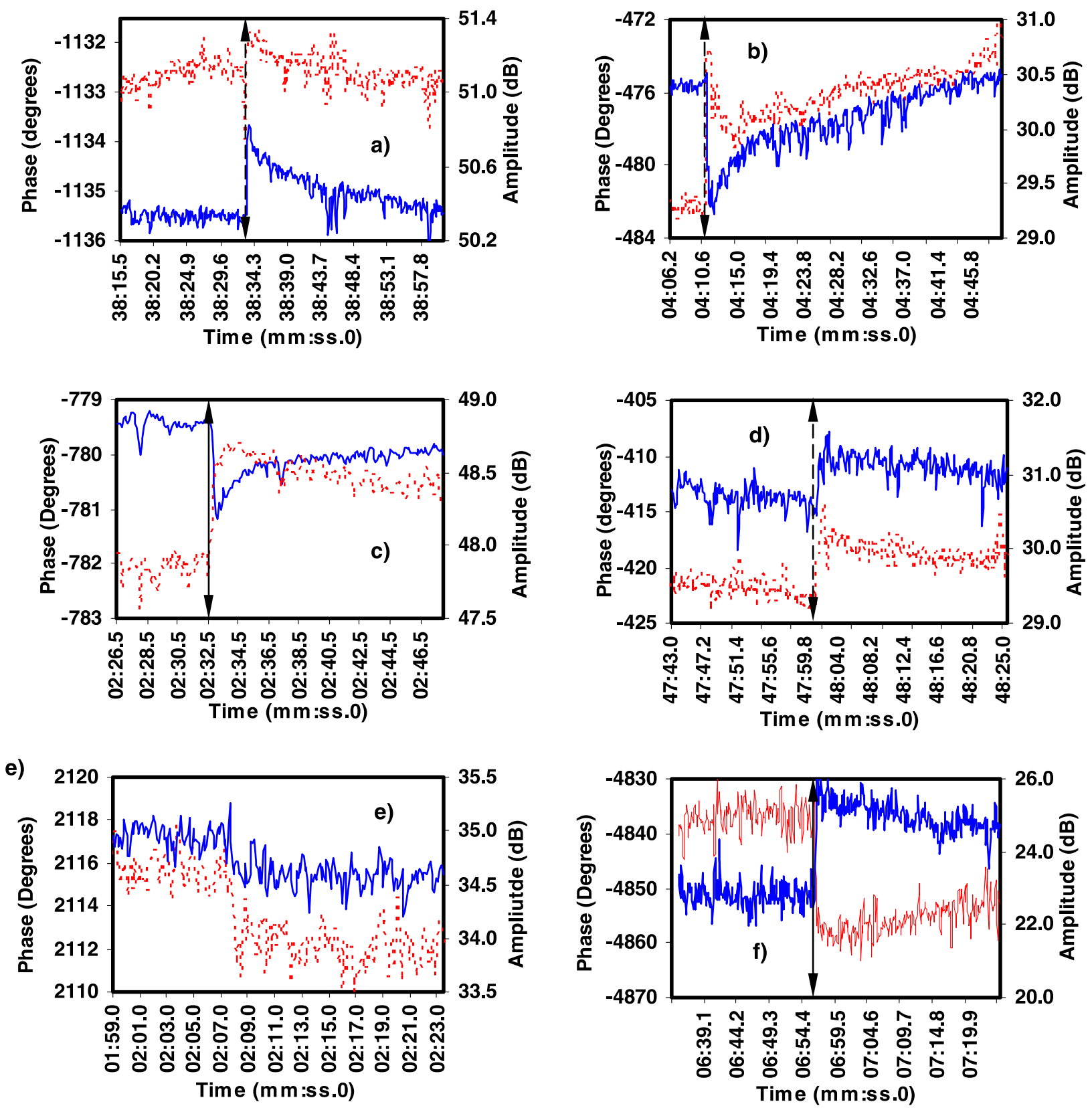

Figure 4. Typical examples of observed amplitude (solid trace) and phase (dotted trace) perturbations: (a) early/fast event on 22 November at 12:38:33.2 h UT, on NWC, (b) early/fast event on 29 November at 18:04:10.9 h UT, on NWC, (c) early/slow event on 23 November. at 13:02:32.6 h UT on NWC, (d) early/fast event on 10 November at 10:48:01.2 h UT on NPM, (e) early/fast event on 9 November at 16:06:56.1 h UT on NPM, (f) early/fast event on 23 November 2006 at 14:02:07.7 h UT on NPM. Dashed vertical lines with arrows in panels $\mathrm{a}, \mathrm{b}$ and $\mathrm{d}$ indicate the time of WWLLN-detected lightning. Solid vertical lines with arrows in panels $\mathrm{c}$ and $\mathrm{f}$ indicate the time of radio sferics observed at Suva.

slow event given in Figure 4c. Such sferic cluster is most likely associated with intracloud lightning (IC) indicating the possibility of IC lightning activity associated with this early/ slow event. At Suva, early/slow events are observed very rarely and in the nighttime only, indicating that not all IC flashes result in early/slow events. The early/fast event on NPM signal shown in panel $\mathrm{f}$ of Figure 4 also occurred during the time of wideband data recording. The spectrogram in Figure $5 \mathrm{~b}$ obtained from wideband VLF data analysis revealed the existence of strong dispersed sferic (tweek) coincident with the early/fast event observed on NPM signal on 23 November at 14:02:07.66 h UT. This particular sferic has both ELF and VLF frequency components indicating that most likely positive CG discharges associated with TLE generated it. Strong positive CG discharges with large return stroke peak current that can trigger the red sprites are associated with ELF radio atmospherics observed at large distances $(\sim 1500 \mathrm{~km})$ from the discharge [Sukhorukov and 

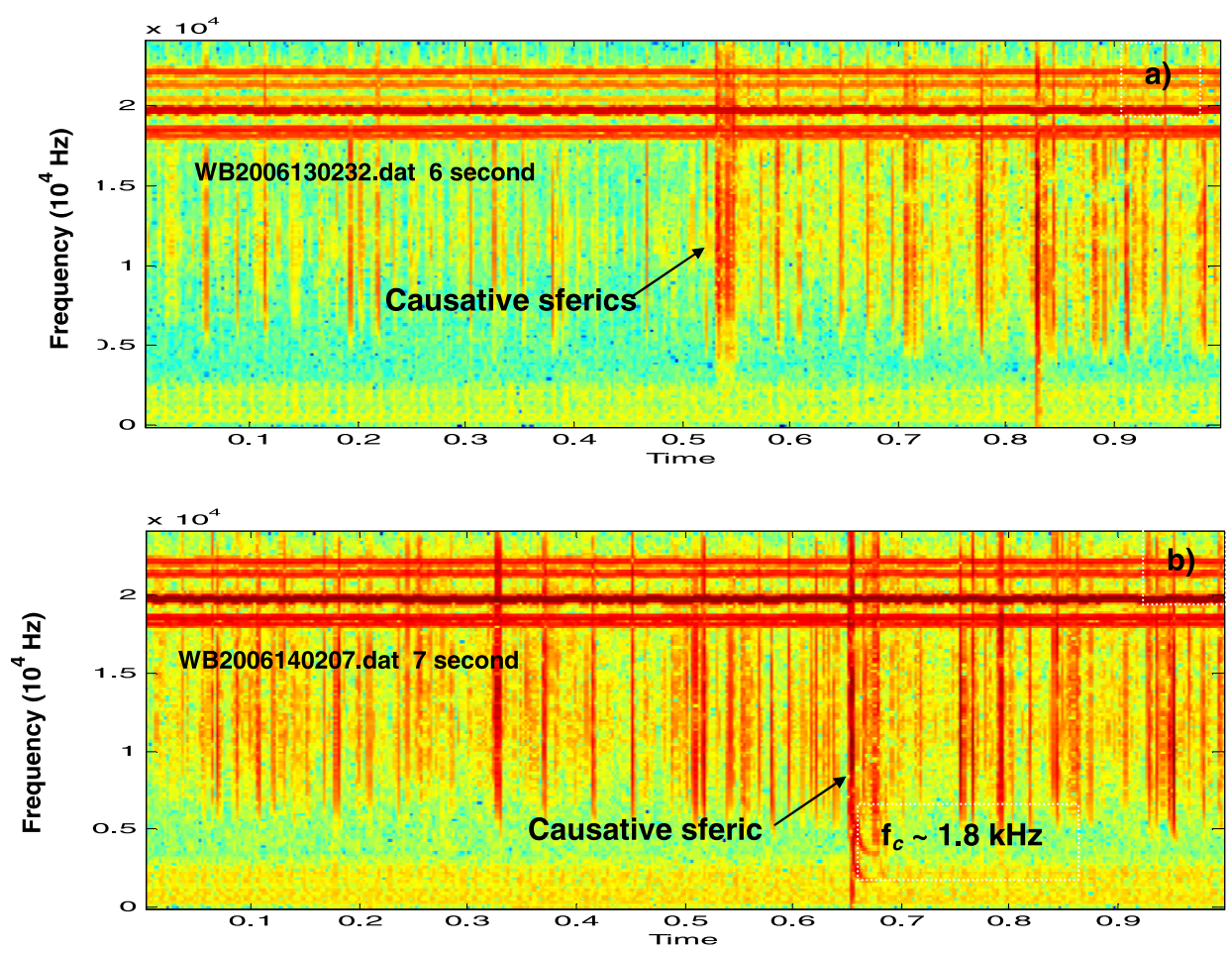

Figure 5. Spectrograms showing the sferics observed on 23 November 06 (a) small sferics cluster at 13:02:32.54 h UT coincident with the early/slow event shown in Figure 4c, and (b) tweek sferic at 14:02:07.65 h UT having both ELF and VLF frequency components associated with the early/fast event shown in Figure 4f.

Stubbe, 1997; Cummer and Inan, 1997; Ohkubo et al., 2005]. The propagation of ELF energy below cut-off frequency $(\sim 1.8 \mathrm{kHz})$ of first order mode of tweek as shown in the spectrogram must occur by quasi-transverse electromagnetic mode waves since other modes at these frequencies will be evanescent. The distance, $d$, traveled by the tweek in the earth-ionosphere waveguide, calculated using the method used by Kumar et al. [1994] is found to be $1400 \mathrm{~km}$. Tweeks propagate by multiple reflections in the earth-ionosphere waveguide. Since the number of reflections and direction of arrival of sferics can not be estimated, the exact location of lighting is not known. However, from the propagation $d$ it can be said that lightning discharge associated with this tweek occurred within the TRGCP range.

\subsection{Daytime Early VLF Perturbations}

[7] The occurrence rate of early VLF perturbations on both the NWC and NPM signals when TRGCP is in daylight is considerably smaller as compared to that when TRCGP is in dark. We have selected typical early VLF events when significant section of TRGCP was in the daylight. In general, the decay rate/recovery time of daytime early/fast events is faster/less as compared to the nighttime early/fast events. This is expected as the VLF reflection height will be lower during the day, and less of the ionization change will be significant when contrasted with daytime electron density altitude profiles. However, in some cases recovery is comparable to the nighttime early/ fast events. This probably indicates the variability in the ionization changes, relative to the ambient day and nighttime electron densities. Figure 6 shows a record of typical early/fast VLF event observed simultaneously on NWC and NPM signals at 06:30:55.8 h UT on 21 November 2006. At the time of occurrence of this event the NPM-Suva path was under sunset (modal interference) and the NWC-Suva path under daylight. This event can be regarded as two step early/fast event which may be produced by two strong lightning flashes or by the first and second return strokes of same lightning separated by $50-100 \mathrm{~ms}$ or so, each associated with strong electromagnetic pulses (EMP). It can be clearly seen that the recovery of this event is faster as compared to the nighttime early/fast events shown in Figure 4 . The strong similarities in the onset and recovery signatures of the perturbation events simultaneously on both signals shown in Figure 6 and also with those presented in Figure 4 is strong evidence that these events were also produced by a lightning discharge-generated ionospheric change, implying a TLE occurring during the day and around the receiver. A sample of about 1.5-min record containing three early/fast VLF events observed on 5 November 2006 at 19:53 h UT (or 06 November at 07:53 h LT) simultaneously on NPM and NWC is presented in Figure 7. At the time of occurrence of these events the NWC-Suva path was under sunrise (approaching modal minimum) and the NPM-Suva path under daytime hence NPM signal strength is more than that of NWC unlike during other events. The time of occurrence of these events is labeled as A, B, C. The events labeled A and B have rather rapid recovery times of about 6 and $15 \mathrm{~s}$ respectively. The decay rate for event $C$ is comparatively larger showing the recovery time of about 20 s. WWLLN did not detect any 


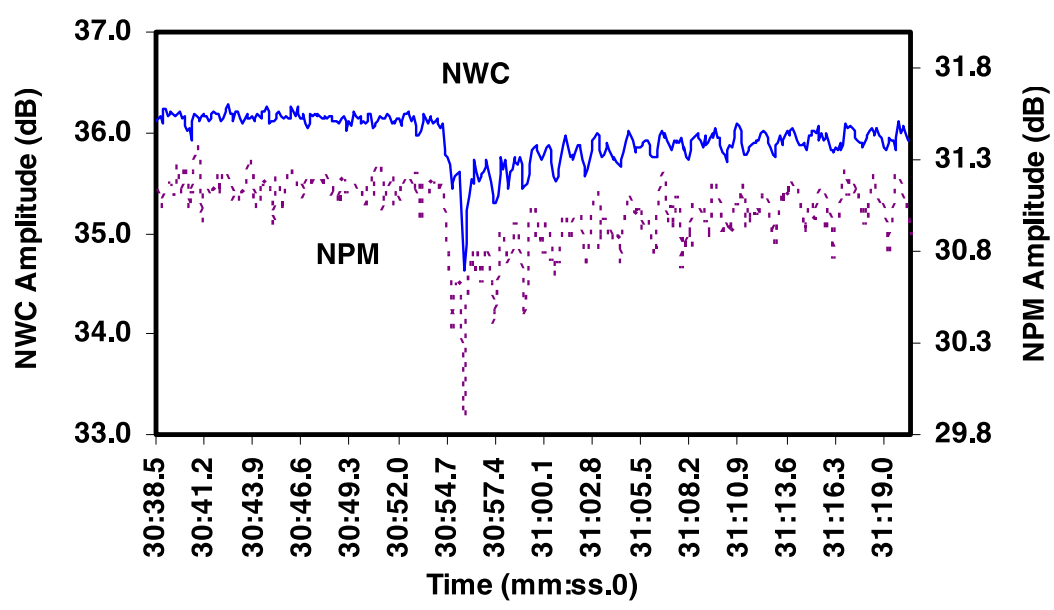

Figure 6. A typical example of daytime early/fast VLF event observed simultaneously on NWC (solid trace) and NPM (dotted trace) signals on 21 November 2006 at 06:30:55.8 $\mathrm{h} \mathrm{UT.}$

lightning within $500 \mathrm{~km}$ of the receiver coincident with the perturbations presented in Figures 6 and 7.

[8] Most of the daytime early VLF perturbations are steplike showing fast (step-like) onset, an amplitude change which remains at the perturbed level for about 2 to $4 \mathrm{~min}$, and then recovers fast (step-like) similar to the onset. The step-like early events show onset and recovery as step-down and step-up and vice versa. They are observed mostly on the amplitude of either NWC or NPM signals and sometimes on both the signals. They dominantly occur during the daytime propagation conditions and are very rare in the nighttime. No such VLF event was observed in the nighttime during the month of November 2006, on both the signals. The typical examples of step-like early events indicating the onset as step-down and recovery as step-up and for which WWLLN detected the lightnings at start and end are presented in Figures 8 and 9. The step-like early VLF event shown in Figure 8 occurred only on NWC signal on 2 November 2006 at 04:42:13.6 $\mathrm{h} \mathrm{UT}$ and ended at 04:47:00.2 $\mathrm{h} \mathrm{UT}$. At the time of occurrence of this event NPM-Suva path was under sunset (near modal minimum) and NWC-Suva path under the daytime propagation conditions. WWLLN detected two lightnings on 2 November one at 04:42:13.598046 h UT, geog. gat. -30.7172 and geog. long 147.8907 and another at 04:47:00.118639 h UT, geog. lat. -29.5446, geog. long. 148.0636. The lightnings coincided well with the start and end of VLF event in Figure 8. These locations of lightnings have been marked by " $4 \mathrm{a}$ " and " $4 \mathrm{~b}$ " in Figure 1 which are at distance of about 500-600 km off the TRGCP of NWC. Figure 9 shows a sample of about one hour amplitude and phase record containing step-like early VLF events (marked as A and B) in the amplitude of both NWC and NPM signals on 23 November 2006. The event marked by B started at 22:15:43.1 h UT which ended at 22:17:55.1 h UT. At this time the NWC-Suva path was under daytime propagation conditions whereas NWC-Suva path was tending toward complete daytime propagation after encountering sunrise fadings. Therefore, the amplitude of NWC signal is increas-

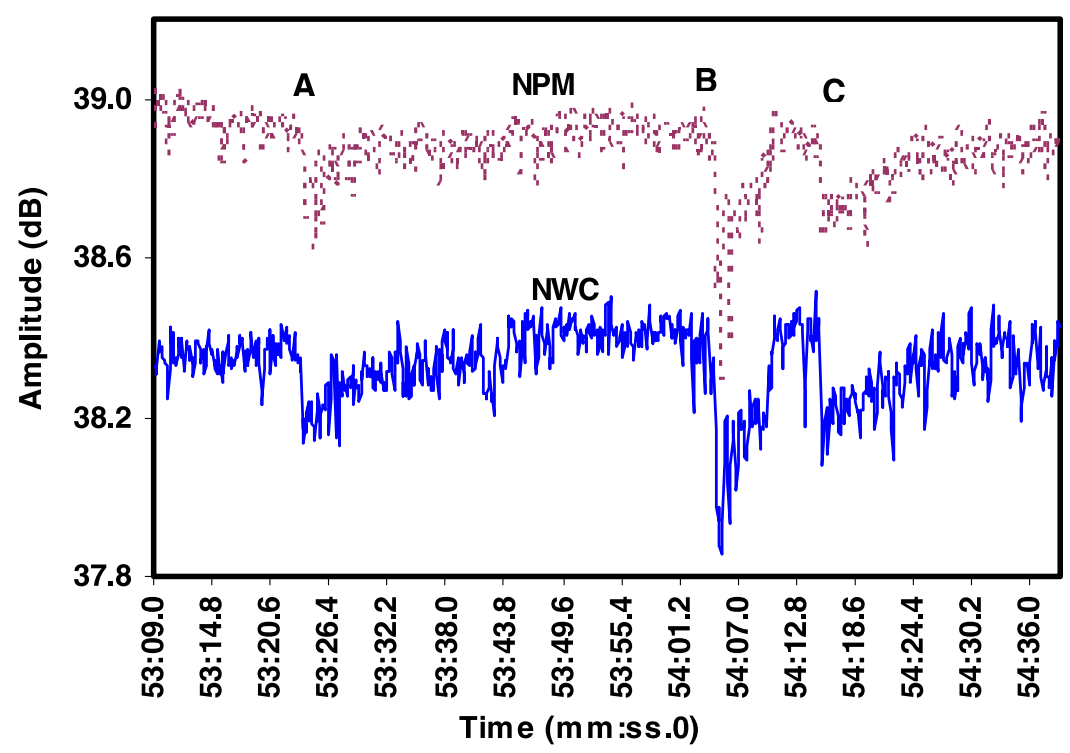

Figure 7. A record of amplitude showing three early/fast VLF events observed simultaneously on NWC (solid trace) and NPM (dotted trace) signals in the daytime on 5 November 2006 at 19:53:09 h UT. 


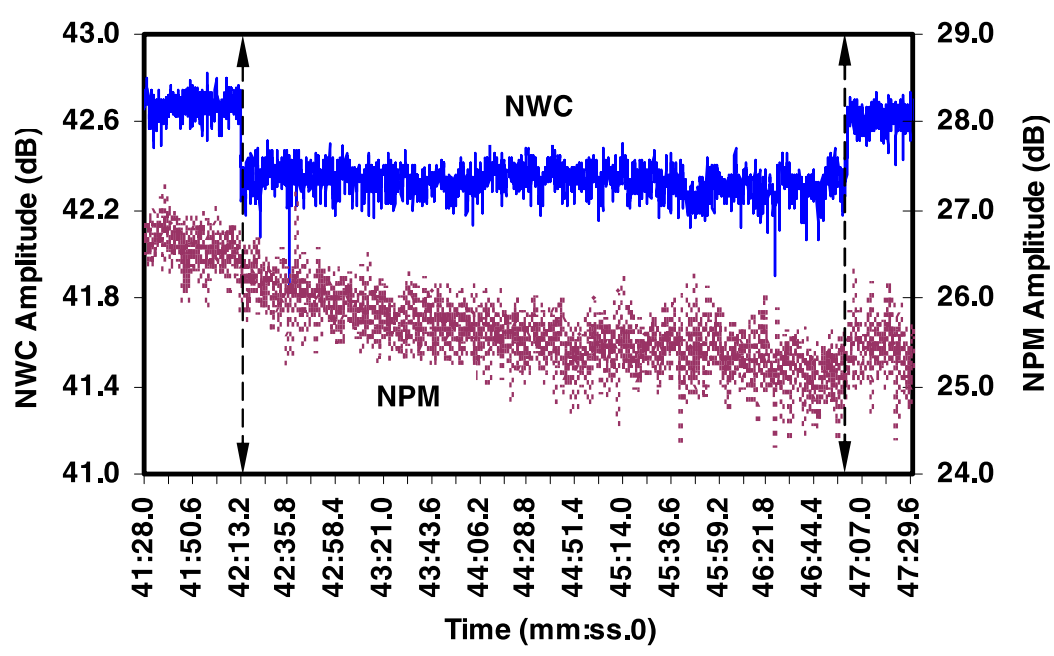

Figure 8. A typical example of step-like early event observed on NWC (solid trace) signal in the daytime on 2 November 2006 at 04:42:13.8 h UT. Dashed vertical lines with arrows indicate the time of associated WWLLN detected lightnings.

ing and the amplitude of NPM signal is almost constant. Phase of NWC signal was not stable during this record. OmniPAL recording of both the signals at Dunedin, New Zealand, for the same duration is shown in lower panel which indicates that at the time of events transmitter power was quite stable. In short-time power off, the amplitude decreases at our site by $\sim 40 \mathrm{~dB}$, whereas the change in amplitude associated with these events is about $0.4-0.6 \mathrm{~dB}$ which falls very well in the range of change in the amplitudes associated with early VLF events as shown in Figure 3. They are not instrumental or experimental since such events were not seen on other transmitters (not shown here) recorded at the same time. Associated with event (B) only, WWLLN detected two lightnings one at 22:15:42.995315 h UT, geog. lat. -7.9569 , geog. long. -174.6567 and another at 22:17:55.0530087 h UT, geog. lat. -11.3159, geog. long. -173.2570 , which have been marked by " $5 \mathrm{a}$ " and " $5 \mathrm{~b}$ " in Figure 1. The locations represented by $5 \mathrm{a}$ and $5 \mathrm{~b}$ are about $50-100 \mathrm{~km}$ and $200-250 \mathrm{~km}$ respectively off the TRGCP of NPM and about 700-1200 km away from receiver and thus the TRGCP of NWC. It appears unlikely that the lightning with such locations can produce/end the VLF perturbation on NWC signal but detectable perturbations for the sprite related events located well off the TRGCP, as long as the sprite lies within $500-1000 \mathrm{~km}$ off the receiver can be observed [Rodger, 1999]. There could be other lightnings in the TRGCP of NWC or near the receiver within $500 \mathrm{~km}$ which coincided with these lightnings and produced step-like early perturbations on NWC but were not detected by WWLLN. The other possibility requires the lightning discharge to affect a vast region of the ionosphere, much larger than expected from elves observations of lightning EMP. Mika et al. [2006] from the observations of VLF transmission and TLEs during EuroSprite2003 have presented the step-like early VLF perturbations associated with the elves. Theoretical models show that strong EMP associated with elves can lead to the ionization increase in the lower ionosphere [Rowland, 1998]. At elves altitudes this ionization is expected to last for few minutes [Rodger et al., 2001] which can lead to step-like early VLF perturbations. For instance, the doubling of the ionization at $90 \mathrm{~km}$ altitude would take about $30 \mathrm{~min}$ to return to $10 \%$ of its ambient value [Rodger et al., 2001]. TLEs are expected to occur both during the day and nighttimes. The elves associated ionization might intrude to daytime VLF reflection heights and lead to step-like early events as presented here.

\subsection{Diurnal Variation of Early VLF Events}

[9] The diurnal variation of occurrence of early VLF events on NWC and NPM signals for November 2006 is presented in Figures 10a and 10b. For each day, the perturbation events were visually inspected, and a count was made of those that appeared to be early VLF events. Early VLF events occur more frequently between 11-21 h UT (23-09 h LT) on NWC signal when the TRGCP is completely or partly in the dark. Previously, early VLF events and TLEs have been reported primarily from nighttime observations; our observations include VLF perturbations during time periods when the entire TRGCP is in daylight. During the one month of data examined in this study, roughly $30 \%$ percent of the VLF perturbations on NWC occurred during daytime propagation conditions with the maximum between $02-05 \mathrm{~h}$ UT and most of which were step-like early VLF events. As noted previously, we are confident that these events are not LEP-produced classic Trimpi, which are very unlikely despite high tropical lightning activity due to increasingly unfavorable gyroresonance conditions [Friedel and Hughes, 1992]. The early VLF events on NPM signal also occur more often between 11-20 h UT when TRGCP is completely or partly in the dark but overall occurrence is less as compared to that on the NWC signal. This is likely to be due to the larger lightning occurrence rates across Australia when contrasted with the NPM-Fiji cross ocean path.

\section{Discussion}

\subsection{Nighttime Early VLF Perturbations}

[10] We have presented the early VLF perturbations (early/fast, early/slow, step-like) observed at a low latitude 

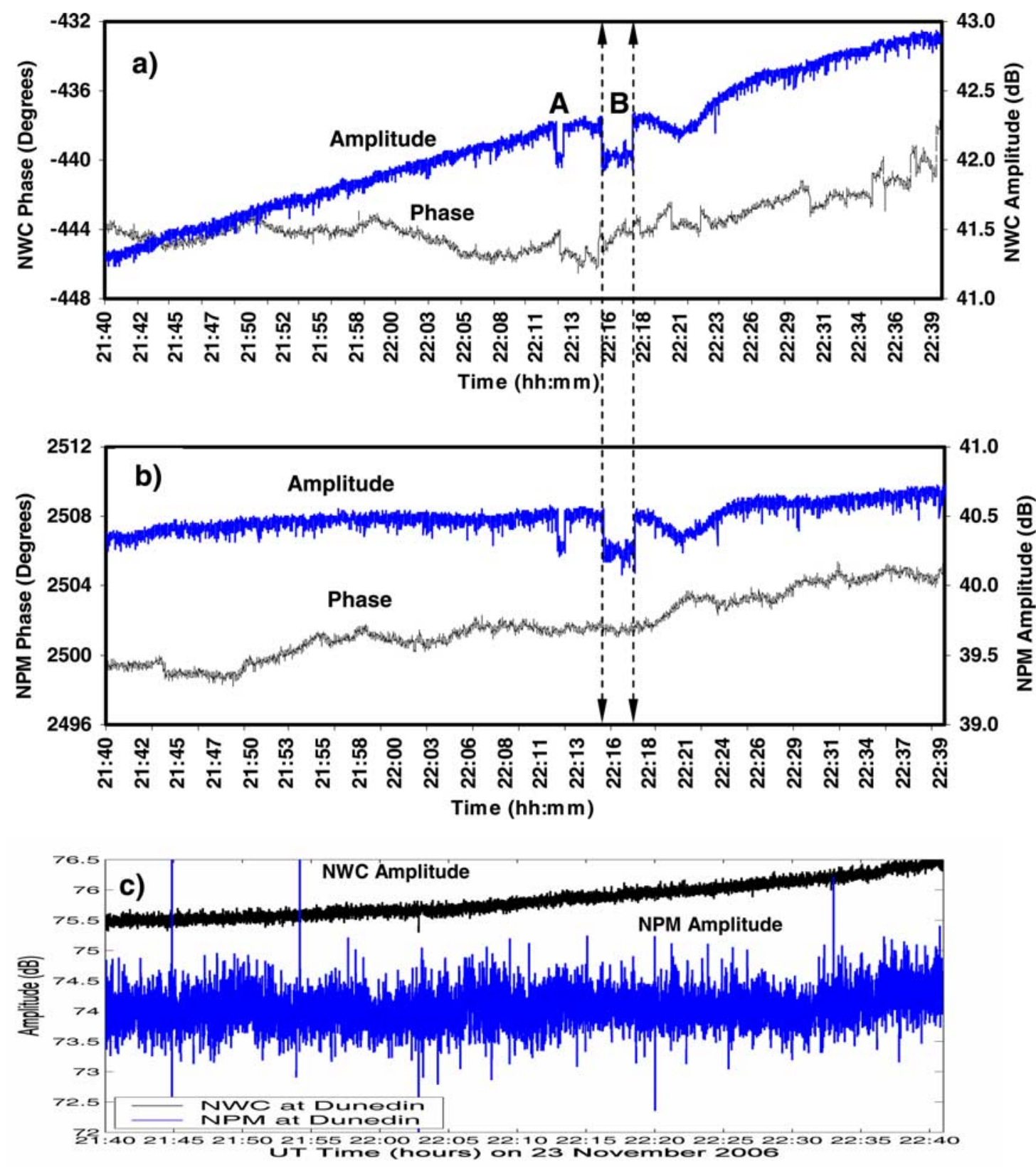

Figure 9. Sample of one hour record at Suva showing typical examples of step-like early VLF events (A and B) observed simultaneously on NWC and NPM signals in the daytime on 23 November 2006 at 22:12:25.5 and 22:15:43.1h UT. Dashed vertical lines with arrows in panels a and $\mathrm{b}$ indicate the time of associated WWLLN detected lightnings for the event B. Panel c shows the amplitude of NWC and NPM signals recorded at Dunedin, New Zealand using OmniPAL data logger, which indicates that at the time of occurrence of events amplitudes of NWC and NPM signals were constant at Dunedin.

station and discuss their association with lightnings detected by WWLLN and radio atmospherics observed at the site. The broadband receiver used in this work is also sensitive to sferics from intracloud (IC) lightnings during thunderstorms. The early/fast VLF perturbations on NWC and NPM signals mostly occur when either entire TRGCP or part of it is in dark. The early/fast events are most common sub-ionospheric VLF perturbations caused by direct lightning effects on the lower ionosphere, and are mostly characterized by abrupt onset followed by slower relaxation times for several tens of seconds. Inan et al. [1995] first observed the connection between the early/fast VLF events for a small subset of sprites occurring near the TRGCP but at large distances from receiver $(>2000 \mathrm{~km})$. They attributed early VLF perturbations to directional (narrow angle) forward scattering from enhanced ionization due to lightning discharge located $\pm 50 \mathrm{~km}$ off the TRGCP and having lateral extent of $\sim 100-150 \mathrm{~km}$. On the other hand, Dowden et al. [1996] observed early VLF perturbations in one-toone relationship with sprites located within $\sim 500 \mathrm{~km}$ around the receiver and attributed to omni-directional (wide-angle) scattering from sprite generated columns of 

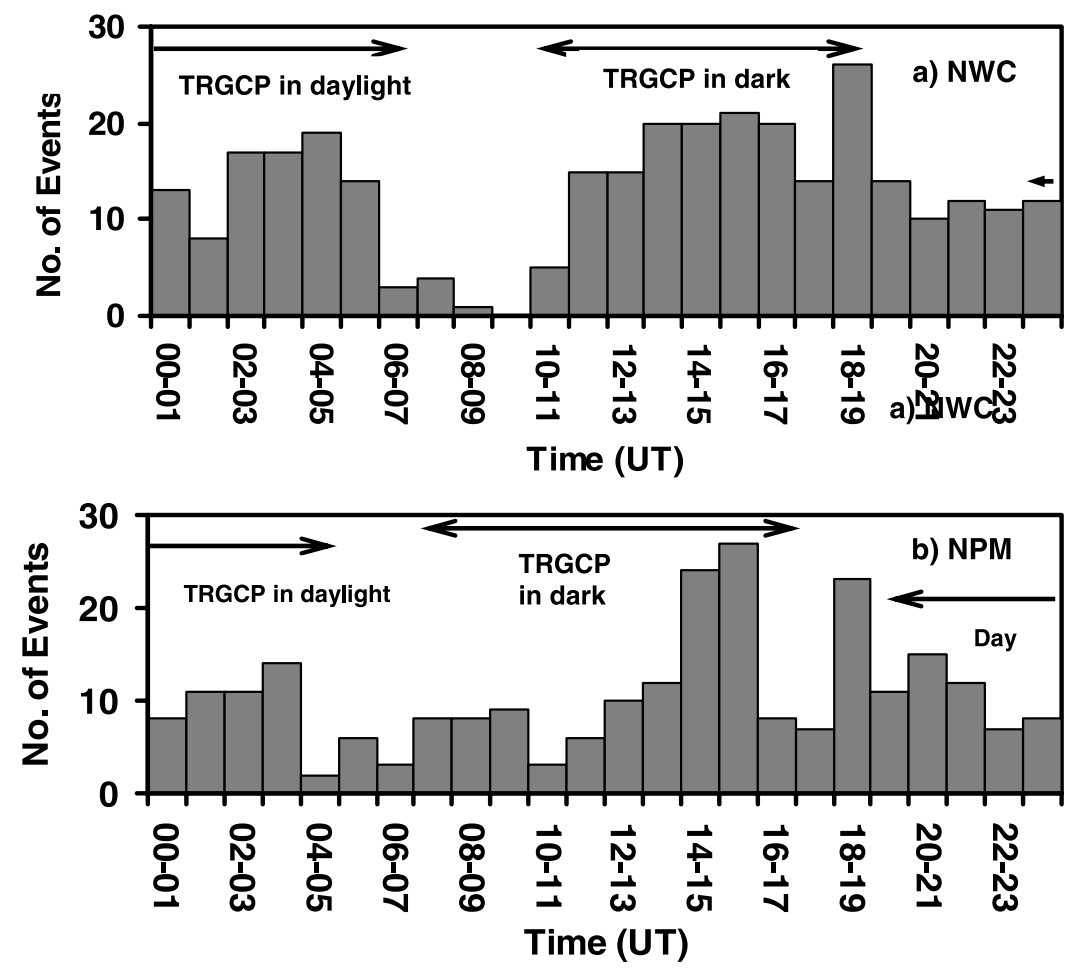

Figure 10. Diurnal variation of number of early VLF events detected during 1-30 November 2006 (a) on NWC signal, (b) on NPM signal.

ionization with shorter scale than the VLF wavelength. The enhancement in the localized conductivity causing early VLF perturbations have been explained by two different processes associated with the direct effect of lightnings: (a) heating of lower ionosphere by strong quasi-electrostatic (QE) field generated by strong lightnings causing the conductivity changes [e.g., Inan et al., 1991; Pasko et al., 1995; Inan et al., 1996a, 1996b], and (b) extra ionization due to transient luminous events (TLEs), such as sprites and elves [e.g., Dowden et. al., 1996; Moore et al., 2003; Rodger, 2003; Mika et al., 2005, 2006]. The mechanism of sustained heating could not be effective for VLF perturbations due to short timescale of the temperature relaxation $(<0.1 \mathrm{~s})$ at the altitude larger than $70 \mathrm{~km}$. The early/fast VLF events shown in Figures $4 \mathrm{a}$ and $4 \mathrm{~d}$ with the locations of causative lightnings within $100 \mathrm{~km}$ off TRGCP and marked by " 1 and 3 " in Figure 1, indicate that these events were produced by narrow angle forward scattering most likely from sprite enhanced ionization. Whereas the early/fast event shown in Figure $4 \mathrm{~b}$ associated with lightning within $350 \mathrm{~km}$ of TRGCP marked by 2 in Figure 1 would most likely imply to the wide-angle scattering. Corcuff [1998] observed early/ fast VLF perturbations in the nighttime associated with lightning discharges situated over France at about $350 \mathrm{~km}$ distances in perpendicular direction to TRGCP. The early/ fast VLF event observed on 29 November on NWC signal shown in Figure $4 \mathrm{f}$ with simultaneous occurrence of strong tweek sferic having ELF $(<1.8 \mathrm{kHz})$ frequency components suggests that this sferic may be produced by strong lightning associated TLEs probably red sprite. About $50 \%$ of ELF sferics with slow tail are associated with sprites [Rodger, 1999]. However, it is not possible to identify whether ELF part is associated with currents flowing within the body of sprites or with the causative lightning discharge. Pasko et al. [1998] have reported that a lightning discharge with larger peak current triggers a sprite within the first millisecond and does not show a separate ELF sferic peak associated with sprites, because the causative lightning and sprite radiate almost simultaneously in time and the electromagnetic radiation in the ELF range produced by sprites could be comparable to that radiated by the causative lightning discharge. The early/slow event observed on 23 November on NWC signal and presented in Figure 4c could be due to CG (not detected) and IC lightnings together. Johnson and Inan [2000] were first to report VLF sferic clusters attributed to IC lightning accompanying a cloud-toground lightning discharge to be consistently associated with early VLF perturbations. The early/slow VLF perturbations with onset durations of 0.5 to $1.5 \mathrm{~s}$ have been reported in association with sprites [Inan et al., 1995; Haldoupis et al., 2006]. Ohkubo et al. [2005] reported an enhanced VLF activity indicative of IC lighting in association with sprites. Johnson and Inan [2000] reported that IC lightning associated with sferics generally do not propagate distances larger than $500-800 \mathrm{~km}$, which is not in agreement with WWLLN observations of IC lightning which are detected by multiple receivers many thousands of km away from the discharge location [Jacobson et al., 2006; Rodger et al., 2006]. Neubert et al. [2005] from observations of TLEs during the EuroSprite2003 have reported that the sprites can also be generated by intracloud lightnings. Haldoupis et al. [2006] have shown that the gradual growth phase of early/ slow perturbations is due to complex and dynamic lightning activity, composed of a few CG return strokes and clusters of IC discharges, which produce primary and secondary ionizations respectively. The long onset duration $(\sim 0.5 \mathrm{~s})$ of 
early/slow events may be due to secondary ionization buildup in the upper D-region below the nighttime VLF reflection heights produced by EMP fields of successive horizontal IC discharges. It can be said that for this particular early/ slow event shown in Figure 4c, the associated sferics seen in Figure 5a can be attributed to the IC lightning activity responsible for secondary ionization due to EMPs heating. The QE fields from sprite associated CG discharges may have produced the ionization (primary) in the upper Dregion which is less substantial than in case of the early/fast events. Since early/slow events are very rare, the analysis of longer duration of VLF data on several transmitters for early/slow VLF events along with broadband data for radio sferics would be useful to further investigate their slow onset.

\subsection{Daytime Early VLF Perturbations: A New Phenomena}

[11] The observations of sprites and elves are not possible in the daylight using the optical measurements. VLF methods can be used to detect red sprites if optical observations are not possible [Dowden et al., 1996; Hardman et al., 1998]. A recently identified red sprite signature observed in infra-sound measurements indicate that sprites continue past sunrise into the daytime, supporting our observations [Farges et al., 2005]. Since the one-to-one correlation of VLF perturbations and sprites is well established, the VLF sprites can be detected when they occur at perpendicular distance of about $50 \mathrm{~km}$ from the TRGCP due to narrow angle scattering [Inan et al., 1995] and about $500 \mathrm{~km}$ around the receiver due to wide-angle scattering and backscattering [Dowden et al., 1996]. The sprites can produce significant ionization enhancements (up to many orders of magnitude) with a horizontal scale of $\sim 80 \mathrm{~km}$ and at altitude of $70-85 \mathrm{~km}$ which is the daytime VLF reflection height and where the timescale for relaxation of electron density enhancement is 10-100 s [Glukhov et al., 1992]. It can be said here that the day-time early/fast VLF events occurring simultaneously both on NWC and NPM signals with recovery times of 5-15 s are most likely associated with sprites occurring in the daylight part around the receiver. The similarities in the onset and recovery signatures of early/fast VLF events observed simultaneously on NPM and NWC (Figures 6 and 7) signals are indicative that they were associated with same lightning located around the receiver. The GCPs of NWC and NPM to Suva are such that the simultaneous occurrence of perturbations on these signals would mainly imply wide-angle scattering on both transmitter signals or narrow angle on one and wide-angle (including backscatter) on the other. There are no reports on daytime early VLF perturbations except on early/short or RORD perturbations observed by Dowden et al. [1994], particularly near local noon and not at night. On the basis of the low occurrence of early/fast events during the daytime as compared to nighttime in the month of November 2006, it can be said that either red sprites occur less often during the day or that the shortest-lived part of the plasma column exists less often below the daytime reflection heights (or some combination of both). Lower recovery times of most of daytime VLF early/fast events compared to nighttime early/fast events indicate the lower timescales for relaxation of electron density enhancements at the daytime VLF reflection heights.

[12] The step-like early VLF events observed in the daylight and as presented in Figures 8 and 9 having the onsets/recovery coinciding with the lightning locations marked by "4(a, b)" and " $5(\mathrm{a}, \mathrm{b})$ " in Figure 1 have not been recognized in the literature previously. However, they were seen rarely in the nighttime sub-ionospheric VLF data [Sampath et al., 2000]. The observations of VLF perturbations associated with lightnings at distances of about $200-$ $600 \mathrm{~km}$ perpendicular to the TRGCP seems to be in disagreement with theory of narrow angle forward scattering since it might imply wide-angle scattering or very large spatial areas of affected ionosphere. It is further interesting to note the step-like recovery of these events coincided with lightnings that occurred at a distance of about $200-600 \mathrm{~km}$ perpendicular to the TRGCP. Theoretical models indicate that strong lightning EMPs can lead to the changes in the ionization in the lower ionosphere [Cho and Rycroft, 1998] and at elves altitudes near the nighttime VLF reflection heights this ionization can last for many minutes [Rodger et al., 2001]. This would lead to step-like early VLF perturbations having long relaxation times due to long lifetimes of electrons at these altitudes [Rodger, 2003]. Mika et al. [2006] observed nighttime step-like early VLF perturbations similar to those reported here associated with elves occurring up to the distances of $400 \mathrm{~km}$ in perpendicular direction to TRGCP implying the wide-angle scattering. Mika et al. expressed the possibility of the sprite occurring below the elves and that accounted for wide-angle scattering. However, Mika et al. did not comment on the step-like recovery of such early perturbations, which can be seen in the data presented in this paper. The observation of step-like early events in the daylight indicates that electron density enhancements associated with elves in some cases may intrude to lower altitudes $(\sim 75 \mathrm{~km})$ or the sprites occurring at the bottom of elves that cause VLF perturbations. Rodger et al. [2001] undertook a simulation study examining the lower ionospheric modification by lightning EMP and have found that both the regions of increases and decreases in the D-region electron density are possible, depending on the relative occurrence of "strong" and "weak" lightning. It is possible that the initial discharge creates an electron density enhancement, which is largely canceled out by the following discharge, all occurring near the daytime VLF reflection height. Clearly, this is an area for further study, both experimentally and theoretically.

\section{Summary}

[13] We have presented recent results on early VLF perturbations observed on NWC and NPM signals during November 2006. Main findings of this study are summarized as follows: (1) The lightnings detected by WWLLN that lie within $50-100$ and $200-600 \mathrm{~km}$ off the TRGCP and occur in simultaneity (just before) of early VLF events may produce narrow and wide-angle scatterings of VLF signals. However, it is not possible here to present the statistics on the early VLF events associated with narrow and wide-angle scattering since the efficiency of WWLLN is low. (2) Simultaneous occurrence of early/fast VLF events on both NWC and NPM signals implies wide-angle 
scattering is common for at least one of the two transmitter signals, with the other signal displaying narrow-angle scattering. (3) The wideband VLF data utilized for radio atmospherics associated with lightning discharges producing early VLF perturbations indicates that the sferic (cluster) most likely associated IC discharges contribute to the long duration onset of early/slow VLF event. The single dispersed sferic (tweek) with large amplitude and having ELF components is most likely associated with sprite producing lightning discharge that generates early/ fast events. (4) Most of the daytime early/fast VLF events have faster recovery rate indicating the faster electron relaxation time of ionization produced by daytime TLEs most likely sprites. The daytime early/fast events seem to have largely escaped from scientific attention since optical observations are not available in the day. (5) Step-like early VLF events are reported for the first time. They are found to occur mainly in the daytime. Detection of lightnings by WWLLN at the end of step-like early events and near the location of lightning that initiated these events indicates the possibility of sharp and sufficient decrease in the electron density caused by the comparatively weaker lightning-EMP by increasing the attachment rate without causing significant ionization responsible for step-like early recovery.

[14] It is now believed that TLEs associated with sprites in the ionosphere have nearly one-to-one correlation with early VLF events [Haldoupis et al., 2004; Dowden et al., 1996; Inan et al., 1996a, 1996b; Mika et al., 2005]. VLF methods can be used to detect red sprites if optical observations of sprites are not possible [Dowden et al., 1996]. Considering lightnings associated with TLEs occurring around the receiver produce early/fast events on both the signals simultaneously, VLF perturbations as presented here can be used to detect mainly the sprites and elves (at least in some cases) in the absence of optical data in the daytime.

[15] Acknowledgments. Authors (SK and AK) are thankful to the Faculty Research Committee, The University of the South Pacific for providing financial support for carrying out this work. All authors wish to thank R. L. Dowden, Director, LF-EM Research Ltd, Dunedin, New Zealand for experimental and scientific support.

[16] Amitawa Bhattacharjee thanks Colin Price and another reviewer for their assistance in evaluating this paper

\section{References}

Armstrong, W. C. (1983), Recent advances from studies of the Trimpi effect, USA, Antarct. J. U. S., 18, 281-283.

Cho, M., and M. J. Rycroft (1998), Computer simulation of the electric field structure and optical emission from cloud-top to the ionosphere, J. Atmos. Sol. Terr. Phys., 60, 871-888.

Clilverd, M. A., N. R. Thomson, and C. J. Rodger (1999), Sunrise effects on VLF signals propagating over a long north-south path, Radio Sci., 34, 939-948.

Corcuff, Y. (1998), VLF signatures of ionospheric perturbations caused by lightning discharges in an underlying and moving thunderstorm, Geophys. Res. Lett., 25, 2385-2388.

Crombie, D. D. (1964), Periodic fading of VLF signals received over long paths during sunrise and sunset, J. Res. Natl. Inst. Stand. Technol., 68, $27-34$.

Cummer, S. A., and U. S. Inan (1997), Measurement of charge in spriteproducing lightning using ELF radio atmospherics, Geophys. Res. Lett., $24,1731-1734$

Dowden, R. L., C. D. D. Adams, J. B. Brundell, and P. E. Dowden (1994), Rapid onset, rapid decay, (RORD), phase and amplitude perturbations of VLF subionospheric transmissions, J. Atmos. Terr. Phys., 56, $1513-1527$
Dowden, R. L., J. B. Brundell, W. A. Lyons, and T. E. Nelson (1996), Detection and location of red sprites by VLF scattering of subionospheric transmissions, Geophys. Res. Lett., 23, 1737-1740.

Dowden, R. L., J. B. Brundell, and C. J. Rodger (2002), VLF lightning location by time of group arrival (TOGA) at multiple sites, J. Atmos. Sol. Terr. Phys., 64, 817-830

Farges, T., E. Blanc, A. Le Pichon, T. Neubert, and T. H. Allin (2005), Identification of infrasound produced by sprites during the Sprite2003 campaign, Geophys. Res. Lett., 32, L01813, doi:10.1029/2004GL021212.

Friedel, R. H. W., and A. R. W. Hughes (1992), Trimpi events on low latitude paths - An investigation of gyroresonance interactions at low L-values, J. Atmos. Terr. Phys., 54, 1375-1386.

Glukhov, V., V. Pasko, and U. S. Inan (1992), Relaxation of transient lower ionospheric disturbances caused by lighting-whistler-induced electron precipitation bursts, J. Geophys. Res., 97, 16,971-16,979.

Haldoupis, C., T. Neubert, U. S. Inan, A. Mika, T. H. Allen, and R. A Marshall (2004), Subionospheric early VLF signal perturbation observations in one-to-one association with sprites, J. Geophys. Res., 109, A10303, doi:10.1029/2004JA010651.

Haldoupis, C., R. J. Steiner, A. Mika, S. Shalimov, R. A. Marshall, U. S. Inan, T. Bosinger, and T. Neubert (2006), "Early/slow" event: A new category of VLF perturbations observed in relation with sprites, J. Geophys. Res., 111, A11321, doi:10.1029/2006JA011960.

Hardman, S. F., C. J. Rodger, R. L. Dowden, and J. B. Brundell (1998), Measurements of the VLF scattering pattern of the structured plasma of red sprites, IEEE Trans. Antennas Propag., 40, 29-38.

Helliwell, R. A., J. P. Katsufrakis, and M. L. Trimpi (1973), Whistlerinduced amplitude perturbation in VLF propagation, J. Geophys. Res., $78,4679-4688$

Inan, U. S., D. C. Shafer, W. Y. Yip, and R. E. Orville (1988), Subionospheric VLF signatures of nighttime D-region perturbations in the vicinity of lightning discharges, J. Geophys. Res., 93, 11,455-11,472.

Inan, U. S., T. F. Bell, and J. V. Rodriguez (1991), Heating and ionization of the lower ionosphere by lightning, Geophys. Res. Lett., 18, 705-708.

Inan, U. S., J. V. Rodriguez, and V. P. Idone (1993), VLF signatures of lightning-induced heating and ionisation of the nighttime D-region, Geophys. Res. Lett., 20, 2355-2358.

Inan, U. S., T. F. Bell, V. P. Pasko, D. D. Sentman, E. M. Wescott, and W. A. Lyons (1995), VLF signatures of ionospheric disturbance associated with sprites, J. Geophys. Res., 22, 3461-3464.

Inan, U. S., A. Slingeland, V. P. Pasko, and J. V. Rodriguez (1996a), VLF and LF signatures of mesospheric/lower ionospheric response to lightning discharges, J. Geophys. Res., 101, 5219-5238.

Inan, U. S., V. P. Pasko, and T. F. Bell (1996b), Sustained heating of the ionosphere above thunderstorms as evidenced in "early/fast" events, Geophys. Res. Lett., 23, 1067-1070.

Jacobson, A. R., R. Holzworth, J. Harlin, R. Dowden, and E. Lay (2006), Performance assessment of the World Wide Lightning Location Network (WWLLN), using the Los Alamos Sferic Array (LASA) as ground truth, J. Atmos. Oceanic Technol., 23, 1082-1092.

Johnson, M. P., and U. S. Inan (2000), Sferic clusters associated with early/ fast VLF events, Geophys. Res. Lett., 27, 1391-1394.

Kumar, S., S. K. Dixit, and A. K. Gwal (1994), Propagation of tweek atmospherics in the earth-ionosphere waveguide, IL Nuovo Cimento, $17,275-281$

Mika, A., C. Haldoupis, R. A. Marshall, T. Neubert, and U. S. Inan (2005), Subionospheric VLF signatures and their association with sprites observed during EuroSprite2003, J. Atmos. Sol. Terr. Phys., 67, 1580-1597.

Mika, A., C. Haldoupis, T. Neubert, T. S. Su, R. R. Hsu, R. J. Steiner, and R. A. Marshall (2006), Early VLF perturbations observed in association with elves, Ann. Geophys., 24, 2179-2189.

Moore, R. C., P. Barrington-Leigh, U. S. Inan, and T. F. Bell (2003), Early/ fast VLF events produced by electron density changes associated with sprites, J. Geophys. Res., 108(A10), 1363, doi:10.1029/2002JA009816.

Neubert, et al. (2005), Co-ordinated observations of transient luminous events during the EuroSprite2003 campaign, J. Atmos. Sol. Terr. Phys., $67,807-820$

Ohkubo, A., H. Fukunishi, Y. Takahashi, and T. Adachi (2005), VLF/ ELF sferics evidence for in-cloud discharge activity producing sprites, Geophys. Res. Lett., 32, L04812, doi:10.1029/2004GL021943.

Pasko, V. P., U. S. Inan, Y. N. Taranenko, and T. F. Bell (1995), Heating, ionisation and upwards discharges in the mesosphere due to intense quasi-electrostatic thundercloud fields, Geophys. Res. Lett., 22, $365-$ 368.

Pasko, V. P., U. S. Inan, T. F. Bell, and S. C. Reising (1998), Mechanism of ELF radiation from sprites, Geophys. Res. Lett., 25, 3493-3496.

Rodger, C. J. (1999), Red sprites, upward lightning, and VLF perturbations, Rev. Geophys., 37, 317-336.

Rodger, C. J. (2003), Subionospheric VLF perturbations associated with lightning discharges, J. Atmos. Sol. Terr. Phys., 65, 591-606. 
Rodger, C. J., M. Cho, M. A. Clilverd, and M. J. Rycroft (2001), Lower ionospheric modification by lightning EMP: Simulation of the nighttime ionosphere over the United States, Geophys. Res. Lett., 28, 199-202.

Rodger, C. J., S. W. Werner, J. B. Brundell, N. R. Thomson, E. H. Lay, R. H. Holzworth, and R. L. Dowden (2006), Detection efficiency of the VLF World-Wide Lightning Location Network (WWLLN): Initial case study, Ann. Geophys., 24, 3197-3214.

Rowland, H. L. (1998), Theories and simulations of elves, sprites and blue jets, J. Atmos. Sol. Terr. Phys., 60, 831-844.

Sampath, H. T., U. S. Inan, and M. P. Johnson (2000), Recovery signatures and occurrence properties of lightning-associated subionospheric VLF perturbations, J. Geophys. Res., 105, 183-191.

Sentman, D. D., E. M. Wescott, D. L. Osborne, D. L. Hampton, and M. J. Heavner (1995), Preliminary results from the Sprite94 aircraft campaign, red sprites, Geophys. Res. Lett., 22, 1205-1208.
Sukhorukov, A. I., and P. Stubbe (1997), On ELF pulses from remote lightnings triggering sprites, Geophys. Res. Lett., 24, 1639-1642.

Voss, H. D., M. Walt, W. L. Imhof, J. Mobilia, and U. S. Inan (1998), Satellite observations of lightning-induced electron precipitation, J. Geophys. Res., 103, 11,725-11,744.

Wescott, E. M., D. D. Sentman, D. L. Osborne, D. L. Hampton, and M. J. Heavner (1995), Preliminary results from the Sprite94 aircraft campaign, blue jets, Geophys. Res. Lett., 22, 1209-1212.

A. Kumar and S. Kumar, School of Engineering and Physics, The University of the South Pacific, Suva, Fiji. (kumarsu@usp.ac.fj)

C. J. Rodger, Department of Physics, University of Otago, Dunedin, New Zealand. 